Proceedings

\title{
Lignocellulosic Biomass as a Source of Raw Materials for the Synthesis of Polyurethanes ${ }^{\dagger}$
}

\author{
Tamara Calvo-Correas ${ }^{1}$, Lorena Ugarte ${ }^{2, *}$, José R. Ochoa-Gómez ${ }^{3}$, Tomás Roncal ${ }^{3}$, \\ Cristina Diñeiro ${ }^{3}$, Maria Angeles Corcuera ${ }^{1}$ and Arantxa Eceiza ${ }^{1}$ \\ 1 'GMT' Materials + Technologies Research Group, Department of Chemical and Environmental \\ Engineering, Faculty of Engineering of Gipuzkoa-Donostia, University of the Basque Country (UPV/EHU), \\ Plaza Europa 1, 20018 Donostia-San Sebastian, Spain; tamara.calvo@ehu.eus (T.C.-C.); \\ marian.corcuera@ehu.eus (M.A.C.); arantxa.eceiza@ehu.eus (A.E.) \\ 2 'GMT' Materials + Technologies' Research Group, Department of Graphical Expression and Project \\ Management, Faculty of Engineering of Gipuzkoa-Eibar, University of the Basque Country (UPV/EHU), \\ Otaola Hiribidea 29, 20600 Eibar, Spain \\ 3 Tecnalia R \& I. Sustainable Chemistry Group, Materials \& Processes Department, Parque Tecnológico de \\ Álava, Leonardo da Vinci 11, E-01510 Miñano, Alava, Spain; jramon.ochoa@tecnalia.com (J.R.O.-G.); \\ tomas.roncal@tecnalia.com (T.R.); cristina.dineiro@tecnalia.com (C.D.) \\ * Correspondence: lorena.ugarte@ehu.eus \\ + Presented at the 2nd International Research Conference on Sustainable Energy, Engineering Materials and \\ Environment (IRCSEEME), Mieres, Spain, 25-27 July 2018.
}

Published: 6 November 2018

\begin{abstract}
Precursors have been satisfactorily synthesized from lignocellulosic biomass for later use in the synthesis of polyurethanes resulting in competitive final properties with those of petroleum derived polyurethanes.
\end{abstract}

Keywords: polyurethanes; lignocellulosic biomass; isosorbide; cellulose

\section{Introduction}

Bioeconomy has a key role in coordinating the development for an increased human well-being with the urgent need to preserve the natural resources, to recycle and to protect the environment. Lignocellulosic biomass (cellulose, hemicellulose and lignin) is considered an ideal source of organic building blocks and a substitute of petroleum for the production of chemical products such as polymers [1]. Moreover, lignocellulosic biomass does not interfere with the food chain. The main objective of this work was to synthesize polyurethanes using biomass derived reactants [2] such as isosorbide (IS) and 2,3-butanediol. Both monomers are derived from glucose, obtained, in turn, from the hydrolysis of cellulose [3,4].

\section{Materials and Methods}

IS derived isosorbide bis((6,6-isocyanatehexane) carbamate) (IS-HDI) was used as diisocyanate. IS-HDI was obtained by reacting isosorbide with HDI in a HDI/IS molar ratio of 2 in acetonitrile (50 $\left.\mathrm{g} \mathrm{L}^{-1}\right)$ at $80{ }^{\circ} \mathrm{C}$ for $2 \mathrm{~h}$ using dibutyl tin dilaurate (DBTL) as catalyst $(0.25 \mathrm{wt} . \% \mathrm{vs}$. IS). Isolation was carried out by cooling the reaction mixture at room temperature and filtering the precipitate off. After drying at $30{ }^{\circ} \mathrm{C}$ IS-HDI was obtained in $63.5 \%$ yield (Scheme 1). 2,3-butanediol (BDO), derived from cellulose, obtained by fermentation [4] was used as chain extender. Poly( $\varepsilon$-caprolactone)diol (PCL) (IoH $=57.22 \mathrm{mg} \mathrm{KOH} \mathrm{g}^{-1}$, ASTM D 4274-88) was used as polyol. 


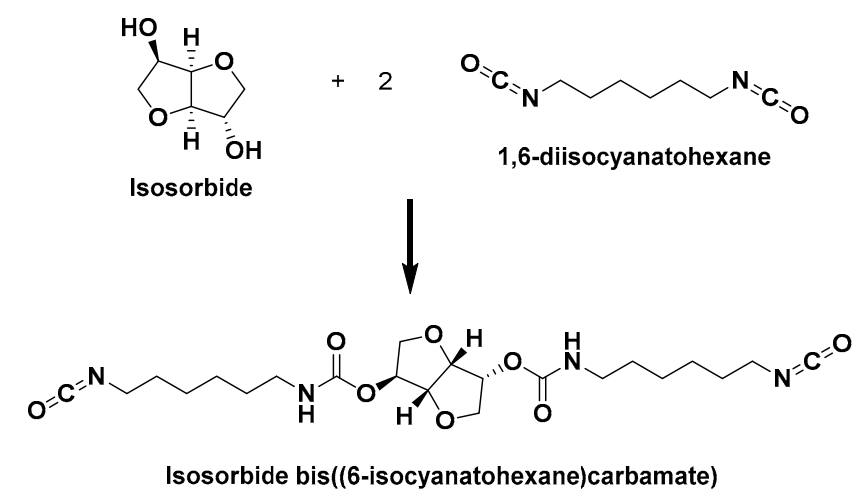

Scheme 1. Synthesis of isosorbide bis((6,6-isocyanatehexane) carbamate).

Polyurethanes were synthesized by two step polymerization without catalyst using anhydrous $\mathrm{N}, \mathrm{N}$-dimethylformamide (DMF) as solvent. Films were prepared by casting on leveled Teflon molds and allowing them to remove the solvent in a vacuum oven at $100{ }^{\circ} \mathrm{C}$ at 900,600 and 200 mbar during 48,24 and $24 \mathrm{~h}$, respectively. The molar ratio and hard segment content (HS) (calculated by the weight percentage of IS-HDI and 2,3-BDO in polyurethane formulation) of the synthetized polyurethanes are shown in Table 1.

Table 1. Designation, molar ratio, IS-HDI content and hard segment content of the synthesized polyurethanes.

\begin{tabular}{cccc}
\hline Samples & $\begin{array}{c}\text { PCL:IS-HDI:2,3-BDO } \\
\text { Molar Ratio }\end{array}$ & $\begin{array}{c}\text { IS-HDI } \\
\text { (wt.\%) }\end{array}$ & $\begin{array}{c}\text { HS } \\
\text { (wt.\%) }\end{array}$ \\
\hline PCL:IS-HDI:2,3-BDO & $1: 2: 1$ & 41.05 & 43.65 \\
PCL:IS-HDI:2,3-BDO & $1: 4: 3$ & 56.15 & 61.48 \\
\hline
\end{tabular}

The obtained films were characterized by means of Fourier transform infrared spectroscopy, differential scanning calorimetry, thermogravimetric analysis and mechanical tests.

\section{Results and Discussion}

Fourier transform infrared (FTIR) spectroscopy was used to identify PU characteristic functional groups and hydrogen-bonding formation. Spectra were recorded using a Nicolet Nexus spectrometer provided with a MKII Golden Gate accessory (Specac) with diamond crystal at a nominal incidence angle of $45^{\circ}$ and $\mathrm{ZnSe}$ lens. Measurements were run averaging 32 scans in the range between 4000 and $650 \mathrm{~cm}^{-1}$ in transmittance mode with a resolution of $2 \mathrm{~cm}^{-1}$. Pure polyol and synthetized PUs spectra are shown in Figure 1a. The band associated to N-H stretching vibration at $3320 \mathrm{~cm}^{-1}$ and the band related to C-N stretching and N-H bending at $1530 \mathrm{~cm}^{-1}$ of urethane group increased as ISHDI:2,3-BDO molar ratio increased, due to the higher quantity of urethane linkages. In order to study the influence of reactants molar ratio in the formation of urethane carbonyl band and also hydrogen bonding, an amplification of the carbonyl stretching vibration band is shown in Figure 1b. Carbonyl group shifts to different wavenumbers if it is free or hydrogen bonded. The stretching vibration bands of free and hydrogen bonded urethane $\mathrm{C}=\mathrm{O}$ groups appear around 1720 and $1690 \mathrm{~cm}^{-1}$, respectively. As IS-HDI:2,3-BDO molar ratio increased, the intensity of hydrogen bonded urethane carbonyl band increased due to higher urethane groups density, while only a shoulder at $1720 \mathrm{~cm}^{-1}$, associated to free urethane $\mathrm{C}=\mathrm{O}$ groups and polyol carbonyl group, can be observed. 


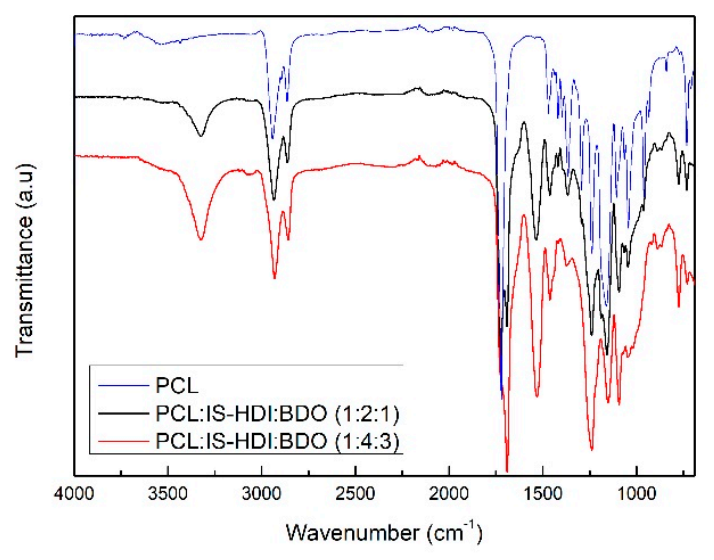

(a)

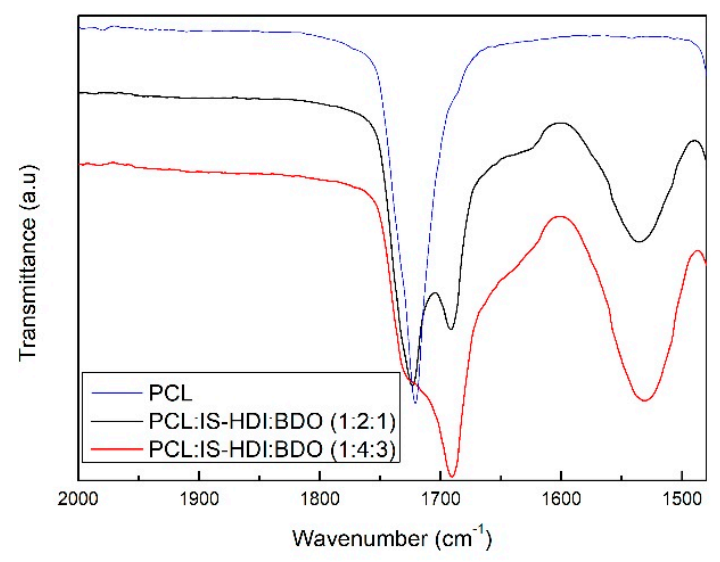

(b)

Figure 1. (a) FTIR spectra of PCL:IS-HDI:2,3-BDO and pure polyol (b) Amplification of carbonyl stretching region.

Thermal properties were determined by differential scanning calorimetry (DSC) using a Mettler Toledo 822e equipment. Samples with a weight between 5 and $10 \mathrm{mg}$ were encapsulated in aluminum pans and heated from -80 to $220^{\circ} \mathrm{C}$ at a scanning rate of $20^{\circ} \mathrm{C} \mathrm{min}-1$ under a constant nitrogen flow. The inflection point of heat capacity change was chosen to determine the glass transition temperature

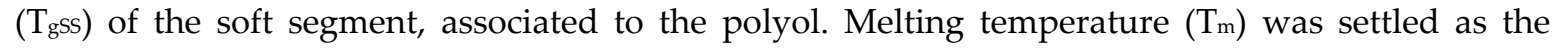
maximum of endothermic peak taking the area under the peak as melting enthalpy $\left(\Delta \mathrm{H}_{\mathrm{m}}\right)$.

As can be observed in Figure 2a, the glass transition temperature corresponding to the polyol ( $\left.\mathrm{T}_{\mathrm{gss}}\right)$, practically did not vary as the molar ratio increased. At greater temperatures, two more transitions were observed, the first one associated with the soft segment and the second one at a higher temperature associated to the hard segment. In the case of the lower molar ratio (1:2:1) the soft segment crystallized $\left(\Delta \mathrm{H}_{\mathrm{msS}}=28.1 \mathrm{~J} \mathrm{~g}^{-1}\right)$ and also in a small extent the hard segment $\left(\Delta \mathrm{H}_{\mathrm{mHS}}=7.3 \mathrm{~J}\right.$ $\left.\mathrm{g}^{-1}\right)$. By increasing the molar ratio (1:4:3), and therefore increasing the hard segment content, the crystallization of the soft segment is restringed, whereas the hard segment crystallized to a greater extent $\left(\Delta \mathrm{H}_{\mathrm{mHS}}=16.1 \mathrm{~J} \mathrm{~g}^{-1}\right)$.

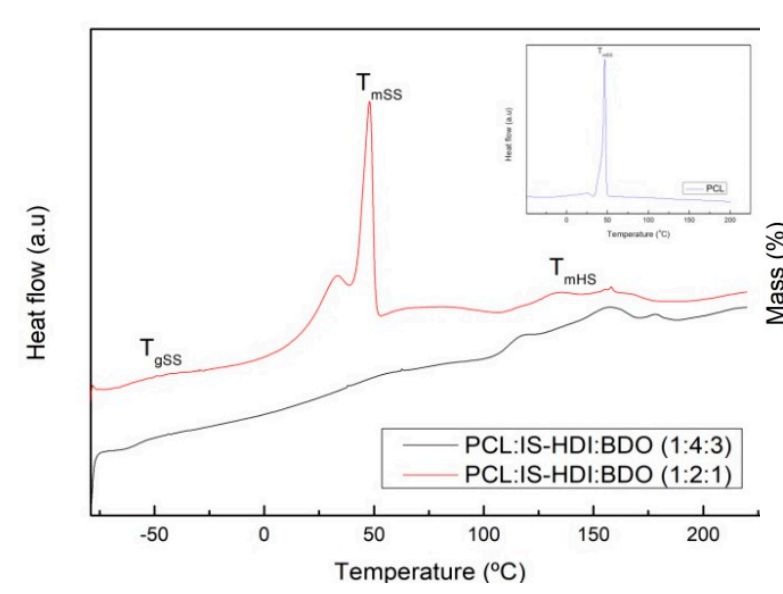

(a)

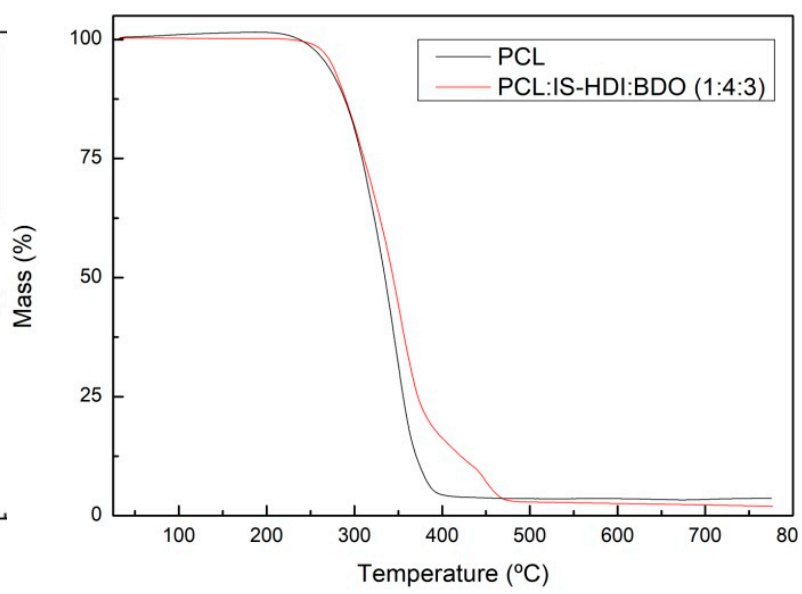

(b)

Figure 2. (a) DSC thermograms of PCL:IS-HDI:2,3-BDO and pure polyol (b) TGA curve PCL:ISHDI:2,3-BDO (1:4:3) and pure polyol.

The thermal stability was analyzed by thermogravimetric analysis using a TGA/WSDTA 851 Mettler Toledo equipment. Samples of 5-10 mg were subjected to a dynamic heating run from 25 to $800^{\circ} \mathrm{C}$ at a heating rate of $10^{\circ} \mathrm{C} \mathrm{min}-1$ in nitrogen atmosphere. Figure $2 \mathrm{~b}$ shows the curve of mass loss respect to temperature of the pure polyol and the synthetized polyurethane with the higher HS 
content. As can be seen in Figure $2 \mathrm{~b}$, the polyol presented a mass loss around $350{ }^{\circ} \mathrm{C}$ (taken as the minimum of the DTG curve). However, two mass losses were observed for the polyurethane, the first one at around the same temperature to that observed in the polyol, could be associated with both segments of polyurethane, the soft and the hard segment. The mass loss observed around $445{ }^{\circ} \mathrm{C}$ could be due to a probable C-C bond cleavage.

Mechanical tests were carried out at room temperature using an Instron 5967 testing machine provided with a $500 \mathrm{~N}$ load cell and pneumatic grips to hold samples. Five replicates of specimens were cut $\left(8 \times 2.5 \times 0.4 \mathrm{~mm}^{3}\right)$ and tested at a crosshead speed of $50 \mathrm{~mm} \mathrm{~min}^{-1}$ to measure tensile modulus, stress at break and elongation at break of synthesized polyurethanes. Table 2 shows the values derived from stress-strain curves. Modulus, stress and strain at break increased with the increase of the hard segment content.

Table 2. Mechanical properties of synthesized polyurethanes.

\begin{tabular}{cccc}
\hline Samples & $\begin{array}{c}\text { Tensile Modulus } \\
\mathbf{( M P a )}\end{array}$ & $\begin{array}{c}\text { Stress at Break } \\
\mathbf{( M P a )}\end{array}$ & $\begin{array}{c}\text { Strain at Break } \\
\mathbf{( \% )}\end{array}$ \\
\hline PCL: IS-HDI: 2,3-BDO (1:2:1) & $170.9 \pm 23.4$ & $7.9 \pm 1.3$ & $15.1 \pm 5.1$ \\
PCL: IS-HDI: 2,3-BDO (1:4:3) & $355.1 \pm 28.3$ & $11.4 \pm 1.8$ & $264.8 \pm 97$ \\
\hline
\end{tabular}

\section{Conclusions}

Isosorbide derived from cellulose was successfully employed in the synthesis of IS-HDI, which was thereafter used in the polymerization in DMF of polyurethanes using 2,3-butanediol, derived also from cellulose, as chain extender, thus supporting the viability of cellulose as a sustainable source of raw materials for chemical synthesis. The synthesized polyurethanes were used in the preparation of films by casting showing competitive properties with polyurethanes from petrochemical origin.

Author Contributions: M.A.C. and J.R.O.-G. conceived and designed the experiments; T.C.-C. and L.U. performed the experiments; L.U. and A.E. analyzed the data; C.D. and T.R. contributed reagents/materials/analysis tools; M.A.C. and A.E. wrote the paper.

Acknowledgments: We thank the Basque Government (IT-776-13, ELKARTEK-KK2017/00003) for the financial support. We also wish to acknowledge the "Macrobehavior-Mesostructure-Nanotechnology" SGIker unit from the University of the Basque Country, for their technical support.

Conflicts of Interest: The authors declare no conflict of interest.

\section{References}

1. Zhou, C.H.; Xia, X.; Lin, C.X.; Tong, D.S.; Catalytic conversion of lignocellulosic biomass to fine chemical and fuels. Chem. Soc. Rev. 2011, 40, 5588-5617, doi:10.1039/c1cs15124j.

2. Calvo-Correa, T.; Martin, M.D.; Retegi, A.; Gabilondo, N.; Corcuera, M.A.; Eceiza, A. Synthesis and characterization of polyurethane with high renewable carbon content and tailored properties. ACS Sustain. Chem. Eng. 2016, 4, 5684-5692, doi:10.1021/acssuschemeng.6b01578.

3. Ochoa-Gómez, J.R.; Roncal, T. Production of sorbitol from Biomass. In Production of Platform Chemicals from Renewable Resources; Biofuels and Biorefineries; Springer: Singapore, 2017; Volume 7, Chapter 9.

4. Roncal-Martínez, T.; Caballero, T.; Díaz de Guereñu-Zabarte, M.M.; Rincón-Arroyo, I.; Prieto-Martínez, S.; Ochoa-Gómez, J.R. Bacterial strain producing 2,3-butanediol and other metabolites. Eur. Pat. Appl. EP16382347, 2016. 